\title{
Selvmordsforebygging blant eldre: Erfaringer med TeleHelp/TeleCheck-tjenesten i Nord-Italia
}

\author{
Ved Diego De Leo og M arirosa Dello Buono
}

\begin{abstract}
Når man snakker om å bruke telefon i selumordsforebygging, tenker man vanligvis på tilgjengeligheten av krisetelefoner. Tradisjonelt sett har dette vaert arbeid utført av frivillige med spesiell opploering $i$ organisasjoner som i beste fall er tilgjengelige for samtaler 24 timer i døgnet. Normalt føres samtalen kun en-til-en med den frivillige, men noen ganger blir innringere også henvist til profesjonelle helsearbeidere innen psykisk helsevern, eller man kobler inn et eksisterende nettverk med muligheter for å intervenere overfor innringeren. I denne artikkelen vil vi redegjøre for en alternativ telefontjeneste for eldre, som man har hatt gode erfaringer med i Italia.
\end{abstract}

De første erfaringene med krisetel efontjeneste fant sted i U SA og Storbritannia før annen verdenskrig. M en de fleste av disse organisasjonene ble etablert på 1960tallet, spesielt etter inspirasjon fra the Samaritansi London og etableringen av the Suicide Prevention Centre i LoS A ngeles (De Leo et al, 2002).

$\mathrm{N}$ år man i dag går inn på Internett og søker etter tel efontjenester som også forebygger selvmord blant eldre, får man referanse til et stort antall tjenester (mellom 67.000 og 87.000). A llikevel er det få vitenskapelige studier av slike tjenester som er tilgjengelige. Basene PubM ed og PsychLit gir ikke mer enn 20 referanser til sammen. $0 \mathrm{~g}$ en nærmere undersøkel se av disse viser at de fleste handler om effekten av sentre for selvmordsforebygging (Dew \& Bromet, 1987; Lester, 1997; Riehl et al, 1988), effekten av oppfølgingssamtaler pr tel efon med pasienter som har vært innlagt for villet egenskade (for eksempel Oyama et al, 2004) eller kvalitative undersøkelser av telefonsamtaler på krisetelefonene fra mennesker i krise (for eksempel G ilat \& Gil, 1998). D et siste emnet som berøres i artiklene vi fant, dreide seg om innovativ bruk av telepsykiatri (Cukor et al, 1998). Den italienske erfaringen med TeleH elp/TeleC hecktjenesten er fortsatt en sentral referanse når det gjelder tilnærminger til selvmordsforebygging blant eldre (De Leo et al, 1995, 2002). I denne artikkelen vil vi utdype formålet med denne tjenesten og hvordan den fungerer.

\section{Oppstarten av TeleHelp/ TeleCheck-tjenesten i Venezia- regionen}

TeleH elp/TeleC heck-tjenesten ble skapt og markedsført av et privat selskap i N ordItalia. I utgangspunktet ble den solgt til myndighetene i Veneziaregionen, som i sin tur tilbød den gratis til innbyggere fra 60 år og oppover som hadde behov for den. $\mathrm{H}$ else- og sosial myndighetene avgjorde hvem som skulle fă tilgang til denne tjenesten ut fra følgende kriterier:

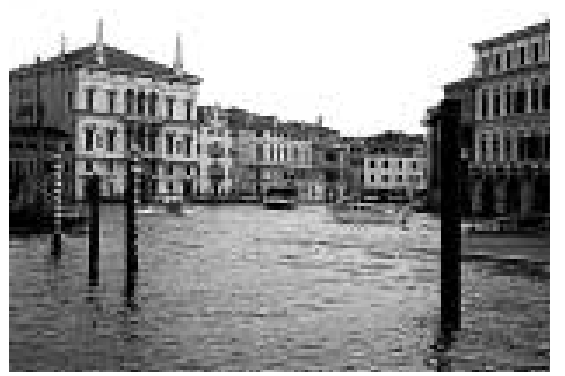

Den ble tilbudt personer som:

a. trenger helsehjelp på en kontinuerlig basis,

b. bor i fjerntliggende områder,

c. har søkt om adgang til offentlige institusjoner (som alders- og sykehjem),

d. er fattige eller ikke får tilstrekkelig støtte av sin familie,

e. som delvis er i stand til å klare seg selv. Tjenesten var dimensjonert for å kunne holde kontakt med 20.000 mennesker, og det var straks behov for en prioritert venteliste. I bunn og grunn var tjenesten blitt etablert med det mål å:

- gi betydelige innsparinger i bruken av skattepengene,

- gjøre det mulig for enslige eldre som var uføre eller i faresonen, å kunne bli boende hjemme,

- gi medisinsk, psykologisk eller sosial assistanse når det var behov for det,

- holde regelmessig kontakt med de eldre, gi dem psykologisk støtte og sjekke regelmessig om de hadde behov for mer assistanse.

TeleH elp/TeleC heck-tjenesten brukte vanlige telefonlinjer og apparater. De som ikke hadde egen telefon, ble knyttet til tjenesten gjennom naboer som var med på opplegget. Tel efonen ga hver av de eldre mulighet til å kontakte tjenesten 24 timer $\mathrm{i}$ døgnet. Enten kunne de ringe selv, eller de kunne trykke på knappen til en trygghetsalarm. Trygghetsalarmen ga kontakt til et lokalt nettverk som kunne rykke ut og gi assistanse. Den var også koblet til et høyttalen de telefonsystem slik at brukeren kunne beskrive hva slags situasjon hun var i. Den sentrale tjenesten holdt kontroll med at de eldre fikk assistanse fra det lokale nettverket innen rimelig tid, og at de lokale hjelperne fulgte de foreskrevne prosedyrene.

TeleC heck-systemet var den mest nyskapende delen av tjenesten. M inst to ganger i uken ble klientene kontaktet av en trenet operatør. Klientene kunne også selv ringe det sentrale kontoret når som helst, og alle henven del ser ble besvart hva enten de gjaldt medisinske, sosiale eller psykologiske spørsmål. Den faste kontakten to ganger i uken ga klientene en jevnlig følelsesmessig støtte. 0 peratørene for TeleC heck-systemet var aldri på hjemmebesøk hos de eldre, og de var aldri involvert i ansikt-til-ansikt-intervensjon. A llikevel skapte de en atmosfære av fortrolighet mellom klient og operatør, og de fikk støtte for å gjøre kontakten mest mulig personlig. $H$ ver operatør hadde ansvar for å ha regelmessig kontakt med omtrent 70 til 80 klienter.

O peratørene var ikke frivillige, men fullt betal te ansatte. Før de fikk begynne i jobben, måtte de igjennom en seks måneders utdanning med vekt på forståelse av medisinske, psykologiske og sosiale aspekter ved eldres liv. Den første utgaven av den alderspsykologiske manualen for operatørene ble skrevet av forfatterne av denne artikkelen mens vi arbeidet ved den psykogeriatriske enheten ved universitetet i Padua.

\section{Etableringen av forskning om fordelene ved telefonassi- stanse gjennom TeleHelp/ TeleCheck-tjenesten}

TeleH elp/TeleC heck-tjenesten viste interessante resultater helt fra begynnelsen av. Kontrollerte undersøkelser av store grupper brukere (kontrollert mot personer på ventelisten og andre potensielle brukere hvis søknader ennå ikke var behandlet) viste positive effekter. Faktisk hadde bruke- 


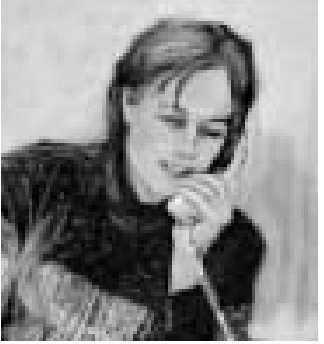

rne av TeleH elp/ TeleC heck-tjenesten det bedre enn kontrollgruppen på en rekke ulike områder:

- De opptok færre plasser på aldershjemmene.

- De brukte færre medisinske tjenester ( sykehus, legebesøk, medikamentforbruk)

- De viste forbedrede kognitive ferdigheter.

- De viste generelle forbedringer i stemninger og livskvalitet.

- De hadde en økt følelse av trygghet. (De Leo et al, 1992)

Interessen for dette systemet har vært overveldende stor helt siden starten, spesielt blant helse- og sosialarbeidere og blant slektningene til de eldre som tjenesten har vært aktuell for. H istorisk sett ble systemet foreslått i en tidsperiode der antall eldre økte dramatisk. Samtidig var det meget tydelig at helsemyndighetene var helt uforberedt på å håndtere den enorme økningen i etterspørsel en etter spesialiserte omsorgstjenester (De Leo et al, 1992). I tillegg gikk selvmordsraten blant eldre stadig oppover på den tiden (De Leo et al, 1997). Dette synes å ha sammenheng med den store omveltningen av de latinske samfunn som var i ferd med å skje, spesielt i forhold til familiestrukturer og verdier (De Leo \& Spathonis, 2003a).

Ikke overraskende møtte TeleH elp/ TeleC heck-tjenesten sterk motstand i begynnelsen. Spesielt møtte den motstand blant de eldre, som hevdet at tel efonassistanse var et kynisk komplott (fra barna og barnebarna) for en delig å bli kvitt dem ved å erstatte den allerede svikten de omsorgen for dem med en slags elektronisk robotassistanse. M ed andre ord, de som mente at de yngre ikke var tilstrekkelig flinke til å besøke sine gamle foreldre før TeleH elp/TeleC heck-tjenesten kom i stand, var redde de etterpå ville ha en unnskyldning for helt å slutte med det. De an så det som mest sannsynlig at tjenesten først og fremst ville skape mer ensomhet og forlatthet.

Faktisk var det noen eldre som fikk tilgang til tjenesten, som meldte seg ut igjen. Likevel var det ganske snart klart for alle og enhver at tjenesten var en suksess i og med at flertallet av brukerne så systemets klare fordeler (De Leo et al, 1992).
U t fra det som hittil er sagt, framgår det at sel vmordsforebygging ikke var blant de opprinnelige målene med tjenesten.

Det tok flere år før noen la merke til den interessante sammenhengen mellom tjenesten og de lave sel vmordsratene hos brukerne (De Leo et al, 1995). Dette viste seg å være et svært viktig resultat i og med at det er allment kjent hvordan eldre har hatt en motvilje mot å kontakte krisesentre og mot å bruke tjenestene innen psykisk helsevern. Resultatene i den første undersøkel sen ble bekreftet av vår langsiktige oppføl gingsstudie (De Leo et al, 2002). D enne studien viste først og fremst at eldre som var brukere av tjenesten, hadde en lavere selvmordsrate enn eldre som ikke var knyttet til tjenesten. Effekten på selvmordsraten var særdeles merkbar blant kvinnene, som også utgjorde flertallet av TeleH elp/TeleC heck-brukerne. Disse kvinnene hadde seks ganger lavere rater for forventet selvmord enn eldre kvinner som ikke brukte systemet. Blant menn var differansen mellom antallet forventede selvmord og registrerte selvmord ikke så stor at det hadde noen statistisk signifikans, selv om antallet faktiske dødsfall var bare halvparten så stort som forventet. $M$ an må ta i betraktning at eldre menn i I talia har mye høyere selvmordsrate enn eldre kvinner (DeLeo \& Spathonis, 2003b). Spesielt gjelder dette de virkelig gamle (de over 80) som er i samme aldersgruppe som klientene av TeleH elp/TeleC hecksystemet (De Leo \& Spathonis, 2004).

Resultatene fra studiene av TeleH elp/ TeleC heck-tjenesten må betraktesi lys av det spesielle utval get brukerne av systemet utgjorde. Faktisk var en stor andel av disse brukerne utsatt for svært mange av de tradisjonelle risikofaktorene for selvmord blant eldre. Depresjon, redusert evne til selvbestemmelse, frykt for å være avhengig av andres hjelp og frykt for å bli plassert på institusjon er allment anerkjent som viktige risikofaktorer for selvmord blant eldre mennesker. H vilken rolle sosial isolasjon spiller i forhold til selvmordsfare, er mer uklart. M en vi vet at eldre som lever i spredtbebygde og fjerntliggende områder, er langt mer utsatt for selvmord enn sine jevnaldrende som bor i bysentra (De Leo \& H eller, 2004).

Den mest innlysende svakheten ved våre undersøkelser var det faktum at vi sammenlignet TeleH elp/TeleC heck-

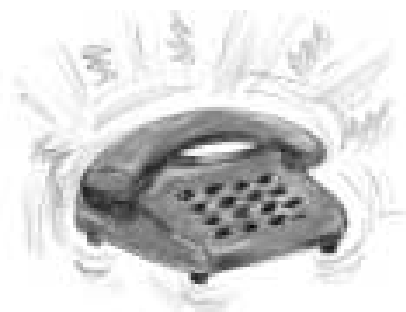

brukerne med befolkningen generelt, og ikke med en kontrollgruppe som delte de samme egenskapene som brukerne av systemet. Det var med andre ord en serie naturalistiske studier som var beheftet med alle de begrensningene som følger med når man ikke gjør randomiserte kontrollerte studier (RCT-studier). M en, spesielt fordi selvmord er et sjeldent forekommende fenomen, har suicidologien fortsatt til gode å se RCT-studier av selvmordsforebyggende arbeid. De studier vi gjorde, ble i hvert fall gjort helt fra starten av da TeleH elp/TeleC heck-tjenesten ble satt i drift. Selv om bedringer i tallene for depresjon, i målene for livskvalitet osv. ikke kan sies å gi belegg for at systemet forebygger selvmord, så er det sannsynlig at disse bedringene også innvirker på antallet selvmord. De observasjonene vi har rapportert her, innebærer derfor et virkelig sjel dent eksempel på en langvarig anvendelse av en strategi for selvmordsforebygging.

En strategi der man aktivt tar kontakt, gir omsorg over lengre tid og gir en økt grad av følel sesmessig støtte, synes å være nøkkelen til å forebygge selvmord. Det er viktig å huske at retningslinjene for å vurdere selvmordsforsøk hos el dre er svært ufullstendige. Eldre forteller faktisk svært sjelden om sine selvmordstanker. T vert i mot prøver de som oftest å skjule dem, og de har lite kontakt med psykisk helsevern (De Leo \& Ormskerk, 1991).

Den mer synlige effekten TeleH elp/ TeleC heck-tjen esten hadde på kvinner, henger sannsynligvis sammen med at kvinnene hadde lettere for å kommunisere sine følelser og for å motta emosjonell støtte. M enn er mindre villige til å uttrykke sine følelser, og de lar seg antakelig ikke involvere i terapeutiske prosjekter der hovedsaken er å sette ord på egen lidelse.

Spesielt for isolerte, bevegel seshemmede, lavt utdannede og sosialt dårlig til passede el dre var tel efonkontakten hjemmefra et bedre alternativ enn ansikttil-ansikt-kontakt. U t fra dette perspektivet er TeleH elp/TeleC heck-tjenesten fremdeles en tjeneste som gir et bemerkelsesverdig antall fordeler for eldre mennesker, og for samfunnet som helhet.

Faktisk tilbys TeleH elp/TeleC heck-tjenesten fortsatt i N ord-Italia i dag fordi den har så god kost-nytte-ratio helt uavhengig av dens selvmordsforebyggen de effekt. 


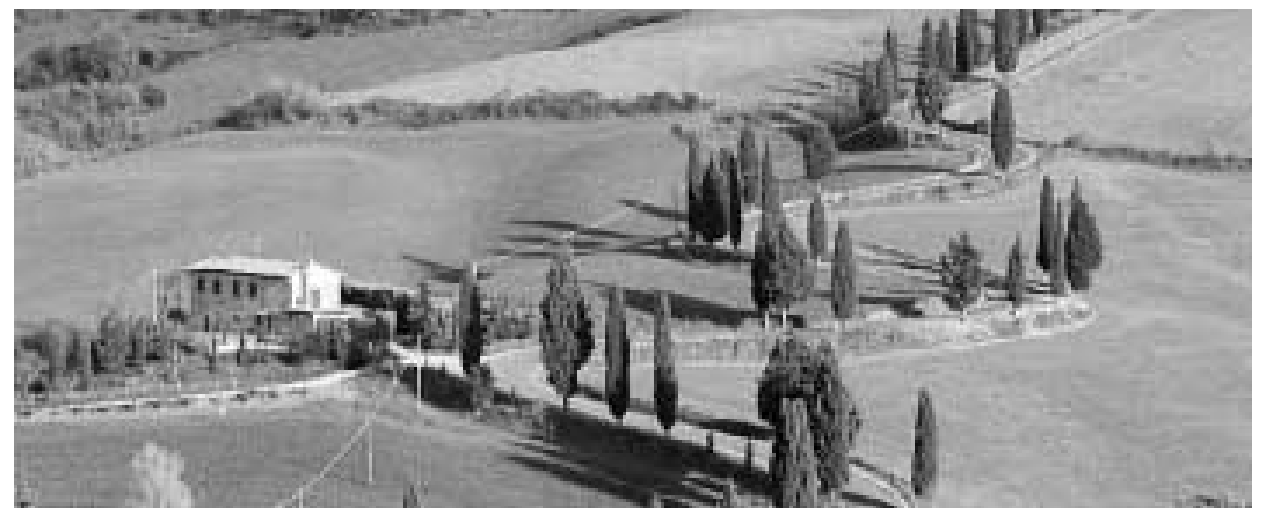

\section{Framtidsperspektiver}

Det er tallrike eksempler på at man har laget systemer som ligner TeleHelp/ TeleCheck-tjenesten rundt omkring i verden. Det systemet som ligner mest, er antagelig systemet som for tiden drives i Tasmania. Den største vanskeligheten med å opprette slike tjenester er behovet for et stort antall lønnede ansatte med spesiell opplæring. Ved iverksetting av strategier som kun er rettet mot selvmordsforebygging har man ikke råd til å ansette så mange operatører som det italienske systemet. På den annen side er det mulig å lage samarbeid med andre organisasjoner, med allmennlegene, geriatere, sosialarbeidere osv., slik at man kan dele på kostnadene. Men slike samarbeid blir ofte ganske komplekse operasjoner som er vanskelige å realisere. Slike samarbeidsprosjekter ville gjort det mye enklere å opprette en TeleHelp/ TeleCheck-tjeneste.

Et annet problem er det tradisjonelle problemet med å identifisere, tilnærme seg og gi effektiv hjelp til eldre selvmordsnære menn. Vi har ikke tilgjengelig noen informasjon som på noen overbevisende måte gir belegg for å si hva som er effektive intervensjoner for eldre menn. Både korttids- og langtidsoppfølgingen av TeleHelp/TeleCheck-tjenesten har mislykkes $\mathrm{i}$ å vise gode resultater for mannlige deltakere (De Leo et al, 1995, 2002). Problemet med å kommunisere med eldre menn er velkjent (Kastenbaum, 1992). Dette er altfor innvevd i tradisjoner og kulturelle verdier til å la seg endre i løpet av en generasjon (De Leo \& Sathonis, 2004).

Det er liten tvil om at morgendagens eldre vil være svært forskjellige fra dagens eldre (i forhold til utdannelse, kunnskaper om psykisk helse, sosiale ferdigheter og dataferdigheter, osv.). Dette bør ikke føre til at vi setter oss ned for å vente og se. I dag følger forskningen på dette emnet tre ulike hovedlinjer, og alle tre er til stede i prosjekter i Australia:

- Tilbud om online-trening i selvmordsforebygging. Dette er basert på en suksessrik læringsmodell (Hawgood $\&$ De Leo, 2002). Tilbudet blir for tiden finansiert av Australias sentrale myndigheter, og det er åpent for profesjonelle, "community gate-keepers" og andre relevante brukere. Evalueringen av prosjektet er fortsatt på et tidlig stadium. og krisehjelp på Internett for spredtbygde og fjerntliggende områder. Denne tjenesten er drevet av et konsortium av universiteter. Det australske instituttet for selvmordsforskning og -forebygging tilbyr ekspertise og arbeidskraft for å møte selvmordsrelaterte problemer. Studien av tjenesten er finansiert av Det australske forskningsråd, og evalueringen av resultatene er i gang.

- Opprettelsen av sykehusbaserte psykogeriatriske enheter som sentraliserer og overvåker alle henvisninger og foresp $\varnothing$ rsler om hjelp fra fjerntliggende helse fasiliteter og pleiehjem. En standardisert klinisk journal med informasjon om kliniske tilfeller blir grundig unders $\varnothing \mathrm{kt}$ ved enheten (navn). Enhetene gir så anvisninger om hvert tilfelle, og resepter på medikamenter blir (lovlig) utskrevet og fulgt opp av de lokale allmennlegene.

Alle disse initiativene har et potensial for å gi en positiv innvirkning på selvmerte menn. Men det er for tidlig å kommentere de foreløpige funnene fra disse initiativene. Det de har til felles, er løftet om hva telekommunikasjonsrevolusjonen vil gjøre med oss (Jones, 2002).

(Artikkelen er oversatt av Henning Herrestad)

D iego De L eo er professor i psykiatri ved Griffith School of Medicine og direkt $\varnothing$ r for Australian Institute for Suicide Research and Prevention i Brisbane, Australia. Han var president i IASP 1999-2003 og var med på å stifte International Academy for Suicide Research, hvor han også har vært president.

D r. Marirosa D ello B uono er psykiater, $\mathrm{PhD}$, med lang erfaring innen alderspsykiatri. Hun er forsker og har privat praksis.
- Tilbud om informasjon, konsultasjoner mordsatferden, spesielt blant eldre depri-

\section{Referanser}

Cukor P, Baer L, Willis BS, Lehay L, O'Haughlen J, Murphy M, Withers M, Martin E (1998): U se of videophones and low-cost standard telephone lines to provide a social presence in telepsychiatry. Telemedicine Journal, 4: 313-321. De Leo D \& Ormskerk S (1991) Suicide in the Elderly: G eneral C haracteristics. Crisis, 12: 3-17. De Leo D \& Spathonis K (2003a) C ulture and suicide in late life. Psychiatric Times, 20, 14-17.

De Leo D \& Spathonis K (2003b) Suicide and euthanasia in late life. Aging Clinical and Experimental Research, 15: 99-110.

De Leo D \& Spathonis K (2004) Suicide A mong the Elderly in Italy: A n Epidemiological Focus in the Light of International Trends. Zeitschrift für Gerontopsychologie \& psychiatrie, 17: 13-22.

De Leo D \& Heller T (2004) Suicide in Q ueens-land, 1999-2001. Mortality Rates and Related Data, Australian Institute for Suicide Research and Prevention, Brisbane.

De Leo D, Carollo G, Dello Buono M (1995) L ower suicide rates with a tele-help/tele-check service for the elderly at home. American Journal of Psychiatry, 152: 632-634

De Leo D, Conforti D, Carollo G (1997) A century of suicide in Italy: A comparison between the old and the young. Suicide and Life-Threatening Behavior, 27: 239-249.

De Leo D, Dello Buono M, Dwyer I (2002) Suicide among the elderly: the long-term impact of a telephone support and assessment intervention in northern Italy. British Journal of Psychiatry, 181: 226-229.

De Leo D, Rozzzini R, Bernardini M, Zucchetto M, Gallato R, Villa A, Dello Buono M, Grigoletto F (1992) A ssessment of quality of life in the elderly assisted at home through a tele-check service. Quality of Life Research, 1:367-374.

Dew MA, Bromet EJ (1987) A quantitative literature review of the effectiveness of suicide prevention centers. Journal of Consulting and Clinical Psychology, 55: 239-249.

Gilat I, Gil ZE (1998) Suicidal calls to a telephone emergency service. Harefuat, 134: 523-591.

Hawgood JL, De Leo D (2002) Suicide Prevention Skills Training: A n A ccredited Training Program. Trainer's M anual. Australian Institute for Suicide Research and Prevention, Brisbane.

Jones BN (2002) Suicide among the elderly: the promise of telecommunications. British Journal of Psychiatry 181: 191-192.

Kastenbaum R (1992) D eath, suicide, and the older adult. Suicide and Life-Threatening Behavior, 22: 1-14. Lester D (1997) T he effectiveness of suicide prevention centres: A review. Suicide and Life-Threatening Behavior 27: 304-310.

Oyama H, Kaida J, Sakashita T, Kudo K (2004) $\mathrm{C}$ ommunity-based prevention for suicide in the elderly by depression screening and follow-up: community mental health around the world. Community Mental Health Journal 40: 249-263.

Riehl T, Marchner E, Moller HJ (1988) Influence of crisis intervention telephone services ('crisis hotlines') on the suicide rate in $\mathbf{2 5} \mathbf{~ G ~ e r m a n ~ c i t i e s . ~}$ In HJ Moller, A Schmidtke, R Welz (eds) Current Issues in Suicidology, Springer Verlag, New York, s. $431-436$. 